\title{
Bromatologia da pimenta malagueta in natura e processada em conserva
}

\author{
Tiyoko NH Rebouças; Renata MV Valverde; Helmo L Teixeira
}

Universidade Estadual do Sudoeste da Bahia, Praça Primavera 40, 45700-000 Itapetinga-BA; tiyoko@uesb.edu.br; natemanguinho@ hotmail.com; helmolima@hotmail.com

\section{RESUMO}

Sendo uma das especiarias mais consumidas no mundo, a pimenta malagueta está presente na culinária brasileira há mais de 500 anos. A crescente procura do mercado interno e externo pelas pimentas provocou a expansão da área cultivada em vários estados brasileiros. Seus teores de vitamina $C$ são superiores aos encontrados no pimentão e demais olerícolas. Obteve-se a caracterização físico-química da pimenta malagueta (Capsicum frutescens) in natura e processadas em conserva e, definiu-se, se após o processamento, a hortaliça apresentou perda na qualidade nutricional, para fornecer subsídios ao desenvolvimento da pesquisa tecnológica e divulgar a espécie. $\mathrm{O}$ estudo foi realizado no período de dezembro de 2010 a março de 2011, na UESB. Para a determinação das propriedades físico-químicas da matéria-prima foram avaliados o $\mathrm{pH}$, acidez titulável e atividade de água $\left(\mathrm{A}_{\mathrm{w}}\right.$ ). Da composição química foram determinados a umidade, cinzas, lipídeos, proteína bruta e vitamina C. Foram escolhidas pimentas in natura e processadas em conservas em estádio de maturação fisiológica completa (maduras), adquiridas dos produtores do Município de Barra do Choça-BA. As análises foram realizadas com três repetições. Foi realizada análise estatística dos dados que foram expressos como média e desvio padrão. Os resultados obtidos para amostras de pimenta in natura e processada para análise de atividade de água, $\mathrm{pH}$ e acidez foram $(0,9893 ; 0,9832) ;(5,48 ; 3,76)$ e $(0,0353 \%$, $0,2046 \%$ ) respectivamente. Para umidade, lipídios, proteínas e cinzas foram $(29,4 \%, 15,3 \%) ;(0,636 \% ; 0,620 \%) ;(4,8 \% ; 4,76 \%)$ e $(0,039 \%$; $0,043 \%$ ) respectivamente e para a vitamina C $121,5 \mathrm{mg} / 100 \mathrm{~g}$ para a in natura e 14,5 mg/100 g para a processada. Conclui-se que, após o processamento, ocorreu perda considerável na qualidade nutricional da pimenta malagueta.

Palavras-chave: Capsicum frutescens, ácido ascórbico, composição química, especiarias, processamento.

\section{ABSTRACT}

\section{Bromatology of fresh and processed chili pepper}

Chili pepper (Capsicum frutescens), which is one of the most widely consumed spices in the world, has been present in Brazilian cuisine for over 500 years. The increasing demand for peppers, from both domestic and foreign caused the expansion of the cultivated area in several Brazilian states. The levels of vitamin $\mathrm{C}$ are higher in chili pepper than in sweet peppers and other vegetables. We obtained the physicochemical characterization of fresh and processed chili pepper and we studied the occurrence of nutritional quality loss after processing to provide subsidies for the development of technological research and to divulge the species. The study was carried out from December 2010 to March 2011, in the Universidade Estadual do Sudoeste da Bahia (State University of Southwest Bahia). For determining the physico-chemical properties of the raw material we assessed the $\mathrm{pH}$, titratable acidity and water activity $\left(\mathrm{A}_{\mathrm{w}}\right)$. From the chemical composition we determined the moisture, ashes, lipids, crude protein and Vitamin C. We selected for the study fresh and processed peppers at full physiological ripeness (mature), acquired from the producers of the municipality of Barra do Choça, Bahia state, Brazil. Analyses were done with three replications. We performed statistical analysis of the data and expressed them as mean and standard deviation. The results obtained for samples of fresh and processed pepper, for water activity, $\mathrm{pH}$ and acidity were (0.9893 and 0.9832), (5.48 and 3.76) and (0.0353 and 2046\%) respectively. For moisture, lipids, crude protein and ashes were (29.4 and $15.3 \%)(0.636$ and $0.620 \%),(4.8$ and $4.76 \%)$ and $(0.039$ and $0.043 \%$ ) respectively and, for vitamin $\mathrm{C}$ were $121.5 \mathrm{mg} / 100 \mathrm{~g}$ and $14.5 \mathrm{mg} / 100 \mathrm{~g}$ for fresh and processed pepper. We concluded that, after processing, a considerable loss occurred in nutritional quality of chilli pepper.

Keywords: Capsicum frutescens, ascorbic acid, chemical composition, spices processing.

\section{(Recebido para publicação em 22 de junho de 2011; aceito em 7 de fevereiro de 2013)} (Received on June 22, 2011; accepted on February 7, 2013)

$\mathrm{S}_{\mathrm{c}}^{\mathrm{e}}$ endo uma das especiarias mais consumidas no mundo, a pimenta está presente na culinária brasileira há mais de 500 anos. A crescente procura do mercado interno e externo pelas pimentas provocou a expansão da área cultivada em vários estados brasileiros, principalmente em iniciativas de agricultura familiar. $\mathrm{O}$ cultivo é feito em praticamente todas as regiões, com destaque para Bahia, Ceará, Minas Gerais, Goiás, São Paulo e Rio Grande do Sul. Além de serem consumidas ao natural, as pimentas abastecem a agroindústria e podem ser processadas e utilizadas em várias linhas de produtos, ocupando lugar de destaque entre as espécies condimentares mais utilizadas, superadas apenas pelo alho e cebola. Apresentam teores de vitamina A e C superiores aos encontrados no pimentão e demais olerícolas produzidas no Brasil (Filgueira, 2008).

No Brasil são produzidas algumas dezenas de cultivares dessas pimentas. Apesar do cultivo ainda ser feito de maneira rústica, é um mercado que movimenta em torno de 80 milhões de reais por ano, incluindo o consumo interno e as exportações. Apenas a comercialização de sementes é responsável por um mercado de mais de três milhões de reais (Guidolin, 2005).

As pimentas (Capsicum spp.) compõem uma importante parte do mercado de hortaliças frescas do Brasil, e também 
do segmento de condimentos, temperos e conservas, a nível mundial (Dutra et al., 2010). Além disso a pimenta tem grande valor nutricional, atribuído às proteínas, glicídios, lipídios, minerais vitaminas, água e celulose ou fibras, que quando em proporções adequadas na dieta, são capazes de assegurar a manutenção das funções vitais do organismo, suprindo suas necessidades de produção de energia, de elaboração e manutenção tecidual e de equilíbrio biológico (Reifschneider, 2000).

A vitamina $\mathrm{C}$, por ser hidrossolúvel e termolábil, é rapidamente oxidada quando exposta ao ar. Por esse motivo, ela é usada como índice de qualidade nutricional de produtos derivados de frutas e vegetais porque, quando comparado a outros nutrientes, esta vitamina é mais sensível à degradação durante o processamento e subseqüente estocagem (Oliveira et al.,1999). De acordo com Lima et al. (2000), a perda de vitamina $\mathrm{C}$ é causada principalmente pela incorporação de ar durante as etapas do processamento que favorece as reações aeróbicas, além da temperatura e tempo de armazenamento, sendo o uso de baixas temperaturas, condição imperativa para a retenção de vitamina $\mathrm{C}$ durante a estocagem.

$\mathrm{Na}$ região de Barra do Choça, o processamento da pimenta, na forma de conservas, destaca-se como alternativa de agregação de valor ao produto. $\mathrm{O}$ processamento é, na maioria dos casos, caseiro, utilizando-se sal, vinagre e cachaça. Entretanto, as indústrias caseiras processadoras de pimentas são carentes de parâmetros físicos, químicos, e microbiológicos. A orientação aos produtores e o monitoramento das características de qualidade do produto constituem uma necessidade para prevenir perdas por deterioração. O objetivo do presente trabalho foi obter caracterização físico-químicas da pimenta malagueta (Capsicum frutescens) in natura e processadas em conserva, além de definir se, após o processamento, a hortaliça apresentou perda na qualidade nutricional, com intuito de fornecer subsídios para o desenvolvimento da pesquisa tecnológica dessa espécie e divulgar o potencial nutritivo dessa hortaliça com e sem o processamento.

\section{MATERIAL E MÉTODOS}

O presente estudo foi realizado no período de dezembro de 2010 a março de 2011 nos Laboratórios de Química Analítica e Bioquímica, Núcleo de Estudos em Ciência de Alimentos (NECAL), Laboratório de Tecnologia de Produtos de Origem Vegetal, da Universidade Estadual do Sudoeste da Bahia (UESB), Campus Juvino Oliveira, Itapetinga-BA.

A matéria-prima foi pimenta malagueta in natura e processada em conserva. Os lotes de pimenta malagueta in natura e a processada em conserva foram adquiridos dos produtores do $\mathrm{Mu}$ nicípio de Barra do Choça, por intermédio da fábrica de pimenta em conserva localizada em Vitória da Conquista-BA. Foram selecionadas pimentas em estádio de maturação fisiológica completa (maduras e vermelhas aptas para o consumo).

Os resultados encontrados pelas avaliações físico-químicas, composição química e determinação do ácido ascórbico dos frutos in natura e processados em conserva foram calculados, obtendo-se as médias e os desvios padrões, utilizando-se o programa Excel. As análises foram realizadas em triplicata. Para as características físico-químicas da pimenta malagueta in natura e processada foram feitas as seguintes avaliações: $\mathrm{pH}$, acidez titulável e atividade de água $(A w)$. A composição foi determinada por meio das análises de umidade, resíduo mineral fixo (cinzas), lipídeos e proteína bruta. $\mathrm{O}$ teor de ácido ascórbico foi determinado pelo método de Tillmans (titulométrico), que se baseia na redução de 2-6-diclorofenol-indofenol (DCFI) pelo ácido ascórbico. As análises foram realizadas em triplicata, segundo as Normas Analíticas do Instituto Adolfo Lutz (IAL, 2008).

\section{RESULTADOS E DISCUSSÃO}

De acordo com os resultados de acidez $(0,0353 \%)$ e $\mathrm{pH}(5,48)$ verificou-se que a pimenta malagueta in natura apresentou baixa acidez e $\mathrm{pH}$ levemente ácido. A pimenta malagueta processada em conserva apresentou alta acidez $(0,2046 \%)$ e $\mathrm{pH}$ mais ácido $(3,76) \mathrm{em}$ relação à pimenta in natura, pois a processada é adicionada de ingredientes (sal, vinagre) $\mathrm{O}$ vinagre, isoladamente, ou vinagre de vinho é o produto obtido da fermentação acética do vinho. Assim como o sal, o vinagre também é utilizado como conservante, diminuindo o $\mathrm{pH}$ do produto.

A pimenta malagueta in natura e processada apresentou um valor de atividade de água alto, na faixa de 0,9893 a 0,9832 respectivamente. $\mathrm{O}$ crescimento de bactérias que influenciam na deterioração é inibido em valores de atividade de água inferiores a 0,90. A maioria das leveduras não cresce em valores abaixo de 0,85 e os fungos abaixo de 0,70. Com poucas exceções é possível afirmar que um alimento será estável, em relação à deterioração por microorganismos, quando sua atividade de água for inferior a 0,60 , valor não encontrado na pimenta malagueta in natura e na processada em conserva.

Comparando os resultados da composição química, observa-se que o teor de umidade para a pimenta malagueta in natura e processada foram 29,4, e 15,3\% respectivamente e para cinzas foram 0,039 e $0,043 \%$, valores próximos aos encontrados na tabela de composição de alimentos para as amostras in natura. (IBGE, 1996). Nota-se que o valor de umidade da pimenta processada em conserva está abaixo do da pimenta in natura, devido à perda de água para a solução de salmoura. A umidade de um alimento está relacionada com sua estabilidade, qualidade e composição e pode afetar tanto seu processamento quanto sua embalagem e estocagem. No que se refere aos teores de proteínas e lipídios, não houve diferença entre as duas amostras. Em relação aos frutos in natura, os resultados do presente trabalho foram próximos aos encontrados na tabela de composição de alimentos (IBGE, 1996).

Verificou-se que o teor de ácido ascórbico das pimentas in natura e processadas foram diferentes, o que pode ser atribuído às variações nas cultivares, genética, maturidade, fertilização, condições ambientais e processamento. (Simmone et al., 1997). Entretanto, o teor de ácido ascórbico, quando comparado com a literatura, está dentro do intervalo teórico encontrado 
Tabela 1. Parâmetros físico-química da pimenta malagueta (Capsicum frutescens) in natura e processada em conserva [phisico-chemical parameters of fresh and processed chili peppers (Capsicum frutescens)]. Itapetinga, UESB, 2011.

\begin{tabular}{lrr}
\hline Parâmetros & in natura & \multicolumn{1}{c}{$\begin{array}{c}\text { processada em } \\
\text { conserva }\end{array}$} \\
\hline Acidez (ácido cítrico) (\%) & $0,0353 \pm 0,043$ & $0,2046 \pm 0,026$ \\
PH & $5,48 \pm 0,053$ & $3,76 \pm 0,021$ \\
Atividade de água (aw) & $0,9893 \pm 0,003$ & $0,9832 \pm 0,001$ \\
Umidade (\%) & $29,4 \pm 0,100$ & $15,3 \pm 0,200$ \\
Lipídios (\%) & $0,63 \pm 0,022$ & $0,62 \pm 0,091$ \\
Proteínas (\%) & $4,8 \pm 0,100$ & $4,76 \pm 0,288$ \\
Cinzas (\%) & $0,039 \pm 0,029$ & $0,043 \pm 0,004$ \\
Ácido ascóbico (mg/100 g de amostra) & $121,5 \pm 0,300$ & $14,5 \pm 0,300$ \\
\hline
\end{tabular}

em outros estudos. Howard et al. (1994) obtiveram teor de ácido ascórbico entre 75-277 mg/100 g de amostra em pimenta malagueta enquanto Castro et al. (2008) verificaram 107,4 mg de ácido ascórbico/100 g de amostra em pimenta malagueta.

No presente trabalho obteve-se perda de 88,06\% de ácido ascórbico da pimenta in natura para a pimenta processada em conserva, valor que pode ser considerado elevado. De acordo com Lima et al (2000), a perda de vitamina $\mathrm{C}$ é causada principalmente pela incorporação de ar durante as etapas do processamento que favorece as reações aeróbicas, além da temperatura e tempo de armazenamento, sendo o uso de baixas temperaturas, condição imperativa para a retenção de vitamina $\mathrm{C}$ durante a estocagem.

As vitaminas são compostos bastante sensíveis podendo ser degradadas por vários fatores, como temperatura, presença de oxigênio, luz, umidade, $\mathrm{pH}$, duração do tratamento a que foi submetido o alimento, entre outros. Portanto, o processamento de alimentos pode alterar significativamente a composição qualitativa e quantitativa destes nutrientes, apesar de tornar os alimentos mais atraentes ao paladar e aumentar sua vida de prateleira. (Correia et al., 2008). Um suco de laranja natural perde o seu conteúdo de vitamina $\mathrm{C}$ após 15 a 20 minutos depois do preparo (efeito da luz); igualmente, a vitamina C também se perde totalmente nas verduras quando as mesmas são cozidas (efeito da temperatura). Esta vitamina também é rapidamente destruída pela ação da luz e sua estabilidade aumenta com o abaixamento da temperatura (Bobbio \& Bobbio, 1992).

Diante desses resultados, pode-se concluir que, após o processamento, ocorreu perda significativa na qualidade nutricional da pimenta malagueta. Pode-se sugerir subsídio para o desenvolvimento da pesquisa tecnológica e divulgar o potencial nutritivo dessa espécie para o desenvolvimento científico de programas de manejo, qualidade das hortaliças e o lançamento de novas cultivares dessa espécie e divulgar o potencial nutritivo dessa hortaliça quando consumida in natura.

\section{REFERÊNCIAS}

BOBBIO FO; BOBBIO FO. 1992. Pigmentos naturais. Introdução à química de alimentos. 2. ed. São Paulo: Varela, cap. 6, p. 191-223.

CASTRO SM; SARAIVA JA; LOPES-DA SILVA JA; DELGADILLO I; LOEY AV; SMOUT C;
HENDRICKX M. E 2008. Effect of thermal blanching and of high pressure treatments on sweet green and red bell pepper fruits (Capsicum annuum L.). FoodChemistry 107: 1436-1449.

CORREIA LFM; FARAONI AS; PINHEIRO SANTANA HM. 2008. Efeitos do Processamento Industrial de Alimentos sobre a Estabilidade de Vitaminas. Alimentos Nutrição. 19: 83-95.

DUTRA FLA; BRANCO IG; MADRONA GS; HAMINIUK CWI. 2010. Avaliação Sensorial e Influência do Tratamento Térmico no Teor de Ácido Ascórbico de Sorvete de Pimenta. Revista Brasileira de Tecnologia Agroindustrial 4: 243-251.

FILGUEIRA FAR. 2008. Novo Manual de Olericultura: agrotecnologia moderna na produção e comercialização de hortaliças. $3^{\mathrm{a}}$ ed. Viçosa: UFV. 2008. 421p.

GUIDOLIN FR. 2005. Resposta Técnica. Disponível em: <http://sbrt.ibict.br/upload/ sbrt214.pdf.>Acesso em: 19/04/2006.

HOWARD LR; SMITH RT; WAGNER AB; VILLALON B; BURNS EE. 1994. Provitamin $A$ and ascorbic acid content of fresh pepper cultivars (Capsicum annuum) and processed Jalapeños. Journal of Food Science 59: 362-365.

IBGE - Instituto Brasileiro de Geografia e Estatística. Estudo nacional de despesa familiar. Tabelas de composição de alimentos. 4 ed. Rio de Janeiro: IBGE, 1996. 137p.

INSTITUTO ADOLFO LUTZ. 2008. Métodos físico-químicos para análise de alimentos. In: ZENEBON O; PASCUET NS; TIGLEA P (coord). São Paulo: Instituto Adolfo Lutz, p. 1020.

LIMA VLAG; MELO EA; LIMA LS. 2000. Avaliação da Qualidade de Suco de Laranja Industrializado. Boletim CEPPA 18: 95-104.

OLIVEIRA MEB; BASTOS MSR; FEITOSA T; BRANCO MAAC; SILVA MCG. 1999. Avaliação de parâmetros de qualidade físicoquímicos de polpas congeladas de acerola, cajá e caju. Ciência e Tecnologia de Alimentos 19: 326-332.

PINTO CMF; SALGADO LT; LIMA PC; PICANÇO M; PAULA JÚNIOR TJ; MOURA WM; BROMMONSCHENKEL SH. 1999. A cultura da pimenta (Capsicum sp.). Belo Horizonte: EPAMIG, 39p. (Boletim Técnico, 56).

REIFSCHNEIDER FJB 2000. Capsicum pimentas e pimentões no Brasil. Brasília: Embrapa Comunicação para transferência de Tecnologia, Embrapa Hortaliças, 113 p.

SIMMONEAH; SIMMONE EH; EITENMILLER RR; MILLS HA; GREEN NR. 1977. Ascorbic acid and provitamin A contents in some unusually colored bell peppers. Journal of Food Composition and Analysis 10: 299-311. 